\title{
Development of infrared and visible endoscope as the safety diagnostic for steady- state operation of Wendelstein $7-X$
}

\author{
by M. W. Jakubowski, C. Biedermann, R. König, A. Lorenz, T. Sunn Pedersen, A. Rodatos \\ and the Wendelstein 7-X team
}

Max-Planck-Institut für Plasmaphysik, Wendelsteinstr. 1, 17489 Greifswald, Germany

\begin{abstract}
One of the main aims of Wendelstein 7-X, a newly built stellarator in Greifswald, is the investigation of quasisteady state operation of magnetic fusion devices, for which power exhaust is a very important issue. The predominant fraction of the energy lost from the confined plasma will be taken by the 10 specially designed discrete island divertor modules, which can sustain up to $10 \mathrm{MW} / \mathrm{m}^{2}$. In order to protect the divertor elements from overheating and to monitor power deposition onto the divertor elements 10 state-of-the-art infrared endoscopes will be installed at W7-X and software is under development for real-time analysis.
\end{abstract}

\section{Introduction}

The newly built stellarator experiment WENDELSTEIN 7-X (W7-X) (see Fig. 1), one of the largest fusion experiments in the world, will start its operation in 2015. The mission of the W7-X is to prove the reactor potential of the optimized stellarator line (following the successful results of Wendelstein 7-AS [1]). A main goal for W7-X is to demonstrate steady-state operation at high heating power and with a performance that extrapolates to an attractive fusion power plant.

a)

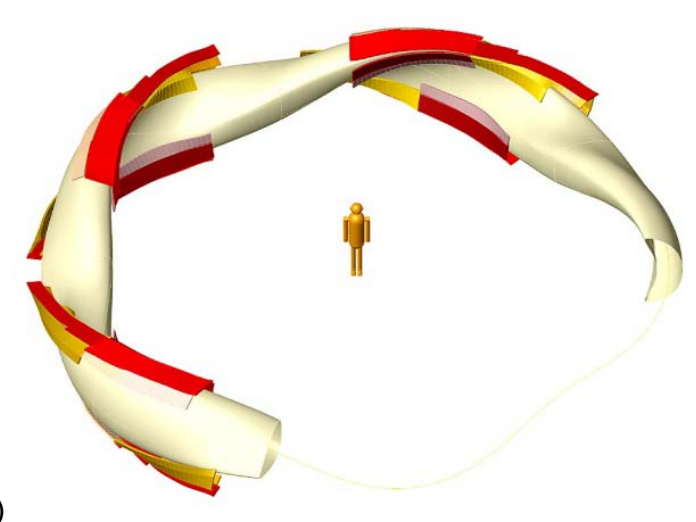

Fig. 1 (a) Helical shape of Wendelstein 7-X plasma with 5-fold symmetry and divertor target elements (red) receiving most of the power loads. (b) Wendelstein $7-X$ with visible plasma vessel, superconducting coils and outer cryostat.

The main heating system of the Wendelstein 7-X is Electron Cyclotron Resonance Heating (ECRH), which uses microwave power of $10 \mathrm{MW}$ in continuous wave operation at a frequency of $140 \mathrm{GHz}$ [2]. It is provided by 10 gyrotrons each with an output power of $1 \mathrm{MW}$ for up to 30 minutes, i.e. for the whole duration of the plasma discharge. Additionally, for short periods of time (up to $10 \mathrm{~s}$ ) Neutral Beam Injection (NBI) and lon Cyclotron Resonance Heating (ICRH) together with ECRH will provide up to $24 \mathrm{MW}$ of injected power. Very important here is the durability of the plasma facing components, which will be exposed to high power loads during steady-state discharges.

\section{Power exhaust concept of W7-X}

The predominant fraction of the energy lost from the confined plasma core reaches the plasma edge via crossfield transport and needs to be exhausted in a controlled way. As indicated in Fig. 2a) the power exhaust concept at W7$X$ must cope with a heterogeneous structure of power loads due to the three-dimensional topology of the W7-X magnetic field lines. Additionally the loaded areas can change drastically from one scenario to another. Following the results of 
Wendelstein 7-AS [3] the island divertor concept will be applied for heat and particle exhaust at W7-X. A set of 10 specially designed discrete island divertor modules (Fig. 2(b)) will be used to achieve high power load handling.

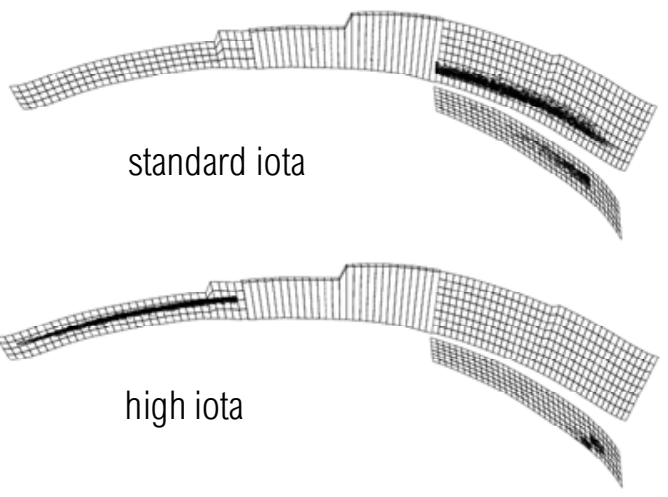

(a)



(c)

Fig. 2. (a) Areas of power deposition at Wendelestein 7-X divertor change depending on the configuration. (b) CAD model of W7-X divertor with main components indicated: red indicate high heat flux divertor target plates from Fig. 2(a), blue elements indicate baffle structures and yellow baffle-like elements. (c) Sketch presenting the structure of one of the high heat flux target elements and (d) the actual image of a target element.

The divertors at Wendelstein 7-X (see Fig. 2(b-d)) are composed of high heat load target tiles, which can sustain up to $10 \mathrm{MW} / \mathrm{m}^{2}$ and a lower heat load baffle structure designed for up to $0.5 \mathrm{MW} / \mathrm{m}^{2}$ of continuous power loads. Figure Fig. 2c presents a sketch of internal structure of divertor target plates. The high heat load targets consist of up to $500 \mathrm{~mm}$ long and $50 \mathrm{~mm}$ wide individual target elements which are covered with an on average $6 \mathrm{~mm}$ thick CFC top layer (marked as gray in Fig. 2(c)). This layer is connected via a copper interlayer (yellow and dark orange) to an underlying $\mathrm{CuCrZr}$ cooling block (orange) with 4 cooling water channels. To maintain the functionality of the target plates the interlayer as well as the CuCrZr block may not exceed temperatures of $475{ }^{\circ} \mathrm{C}$ [4]. In case local temperatures exceed this value, the resulting stress can lead to delamination of the CFC layer and eventually failure of these components. Because of this limitation a close control of the target tile temperatures is of utmost importance.

Monitoring of the temperature of individual components through the use of thermocouples is impossible due to the presence of the cooling water channels. Instead, the divertor surface temperature will be measured through infrared light observation. It has been measured in test facility GLADIS [5] that the temperature of $475^{\circ} \mathrm{C}$ at the position of the soft copper interlayer corresponds to a CFC target surface temperatures of about $1200^{\circ} \mathrm{C}$ which is therefore the maximum allowed surface temperature. In order to measure the expected power fluxes reaching divertor target plates of W7-X one needs to be able to monitor surface temperatures in a rather wide range, i.e. $150^{\circ} \mathrm{C} \leq \mathrm{T}_{\text {surf }} \leq 1500^{\circ} \mathrm{C}$. At present there are several types of the infrared cameras, which are able to detect such surface temperatures. In magnetic fusion devices it is very common to monitor plasma facing components with thermographic cameras using Indium Antimonide (InSb) detectors working at the wavelength range of 3-5 $\mu \mathrm{m}$. Fortunately, due to recent developments in the market of infrared sensors, InSb sensors can cover a relatively large range of temperatures and offer at the same a very good spatial resolution and a high accuracy of the measurements. This is important for several reasons: 
- As each of the W7-X divertor modules consists of target elements with dimensions of $25 \mathrm{~mm} \times 50 \mathrm{~mm}$ (see Fig. 2(d)) the minimum required optical resolution of the system, which allows measuring surface temperatures of individual target elements, is of the order of $6 \mathrm{~mm}$. Due to several constraints on the thermographic system (e.g. the cameras need to be placed $2 \mathrm{~m}$ away from the observed surfaces, light emitted by the divertor must be gathered through a pinhole and transferred by mirrors outside of the vessel) the diffraction limit at a wavelength of $10 \mu \mathrm{m}$ rather than $4 \mu \mathrm{m}$ and the maximum available chip sizes would achieve with two NIR cameras only about $70 \%$ of the required resolution over the entire field of view [6].

- The InSb cameras have much higher time resolution than the FIR micro-bolometer cameras, allowing to monitor fast transient events and to use them to characterise poorly thermally connected re-deposited carbon surface layers which can result in surface temperatures significantly higher than the CFC block temperature which is the critical parameter for safe divertor operation; i.e. detailed knowledge about the surface layers is required for modelling them and their thermal contact in order to derive the required CFC temperature values at the copper interlayer.

- Working at the wavelength around $1 \mu \mathrm{m}$ the temperature measurements can get corrupted by molecular band line and recombination emission from the plasma edge as well as bremsstrahlung emission [7].

- Competition between parallel and perpendicular transport at the edge of the island divertor [8] leads to a wetted area of order a few centimeters (see Fig. 3). In order to study the physics of the power loads of the island divertor one needs to resolve the temperature distribution with spatial resolution of order a few millimetres.

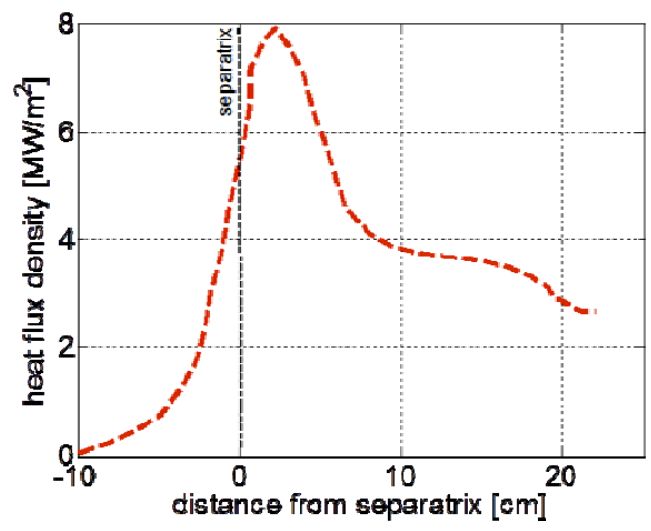

Fig. 3. Simulated heat flux density profile on the surface of Wendelstein 7-X. The abscissa represents the coordinate across the divertor target plates, the ordinate is the projection of the incoming parallel heat flux density on the divertor surface. Figure reproduced from [9]

\section{IR/VIS Endoscope}

The main diagnostic to assure safe divertor operation of Wendelstein $7-X$ will be a set of 10 endoscopes monitoring the divertor and baffles surface and the plasma radiation near their surface. Each endoscope has a Cassegrain optical system designed to observe the $4 \mathrm{~m}$ long and $1 \mathrm{~m}$ wide divertor with a resolution of up to $6 \mathrm{~mm}$ [6], . The image is transferred via complex optics to an infra-red and a visible camera and through a separate window via optical fibres to spectrometers for detailed plasma edge studies in the UV/visible/IR range. The front part of the endoscope needs to be actively cooled in order to keep the endoscope housing at temperatures well below $150^{\circ} \mathrm{C}$. Otherwise it would make infrared monitoring of the divertor surface very difficult and could even lead to damage of some of its components.

As presented in Fig. 4, each endoscope is equipped with a complex system of mirrors and lenses, allowing the observation of the divertor surface in infrared $(3-5 \mu \mathrm{m})$ and visible $(350-800 \mathrm{~nm})$ light. Photons enter the endoscope through a pinhole and are directed via two mirrors (M1, M2 in Fig. 4) onto the off-axis Cassegrain optical system (M3, M4). The off-axis design helps to avoid diffraction due to central obscuration (typical for a Cassegrain system), which would deteriorate the quality of the image. From the M4 mirror, light passes through the window W2, where it is divided by the dichroic beam splitter (B1) into a visible and infrared beam and after passing through a set of correcting lenses it is detected by the sensors in cameras (C1 and C2). Mirror M5 and window W1 provides additional optical access to the entire divertor region and can therefore, with a flip mirror, be simultaneously used for divertor illumination required for in- 
vessel inspection with the visible camera and for imaging any section of the divertor onto optical fibre rows connected to various spectrometers for edge and divertor plasma studies.

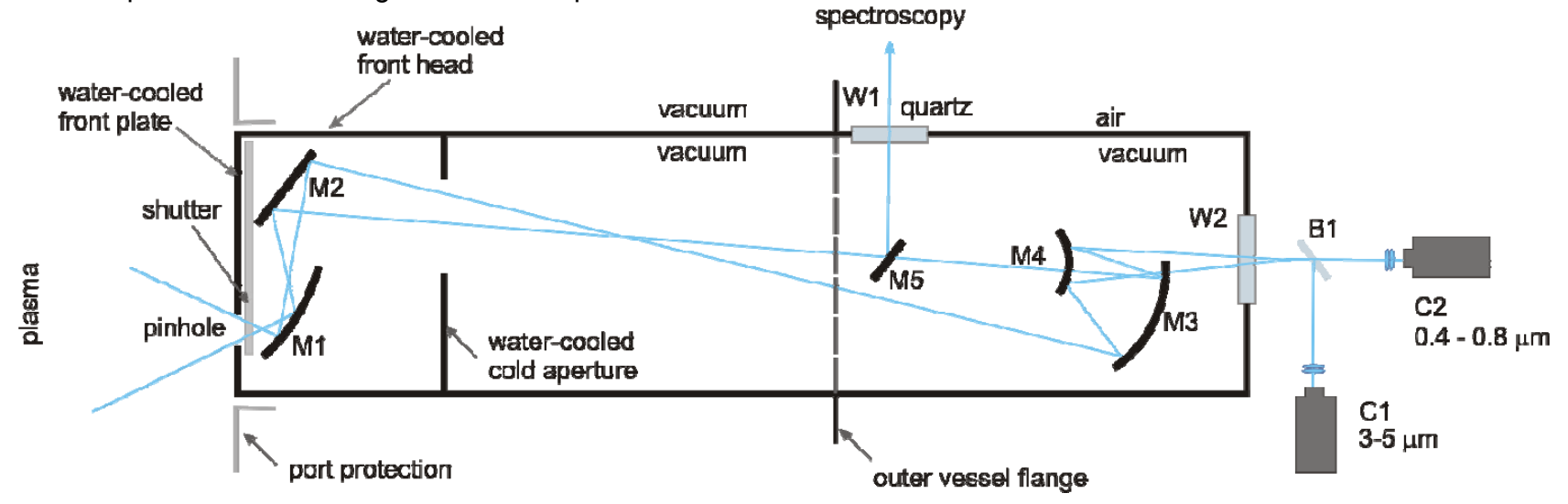

Fig. 4. Schematic picture of the divertor endoscope.

The W7-X ECRH system can provide $10 \mathrm{MW}$ of heating power for up to $30 \mathrm{~min}$. In X2 mode, this radiation is well absorbed by the plasma for densities below the cut-off density of $1.25 \times 10^{20} \mathrm{~m}^{-3}$. However, for higher densities, the non-absorbed power fraction can be on the order of $20 \%$ or even higher, but is operationally limited to at maximum $1 \mathrm{MW}$, resulting in maximum ECRH stray radiation levels of $100 \mathrm{~kW} / \mathrm{m}^{2}$ near the endoscope port of which $1.6 \%$, corresponding to $1.6 \mathrm{~kW} / \mathrm{m}^{2}$, which would be absorbed in a $12 \mathrm{~mm}$ thick sapphire window. This is insignificant compared to the expected $50 \mathrm{~kW} / \mathrm{m}^{2}$ plasma radiation at wavelengths shorter than $6 \mathrm{~nm}$ [10], which will be fully absorbed by any window material. Laboratory experiments have shown that the temperature of such a sapphire window, if actively water cooled, could be kept below $170^{\circ} \mathrm{C}$, which would probably still be acceptable for divertor temperature monitoring at high power operation The entering ECRH stray radiation through a pinhole with diameter of $10 \mathrm{~mm}$ is on the order of $8 \mathrm{~W}$, which can lead to significant thermal loads on sensitive strongly absorbing, e.g. ceramic, components during a 30 minutes long discharge. A significant fraction of this radiation, let's assume here half of it, will be transferred though the endoscope via the metal mirror optical system, but behind the vacuum window this radiation spreads out geometrically, resulting in a power reduction of a factor of about 120 till the detector and will experience an additional $\sim 20 \%$ absorption within the lens system. If the detector would fully absorb the ECRH stray radiation this would then correspond to about $26 \mathrm{~mW}$ distributed over a $1280 \times 1024$ pixels detector or $0.02 \mu \mathrm{W} /$ pixel. This would results in a temperature increase of one pixel at the order of $\Delta \mathrm{T} \approx 0.01 \mathrm{~K}$ per $1 \mathrm{~s}$, which is fully manageable by the attached to the sensor Stirling cooler. Should the $\mathrm{ECRH}$ stray radiation prove to be a problem, unfortunately, neither metal shielding meshes can be used due to the resulting image deterioration nor special protective window coatings, as exist only for visible range (ITO), are presently available. As the absorption coefficients of stainless steel is only on the order of a few percent, the rest of the stray radiation will form an equilibrium inside the endoscope, as it will undergo a very large number of reflections from the surface until it is finally absorbed. Therefore, any element with an absorption coefficient higher than stainless steel will receive a significant fraction of the power that enters the endoscope. To minimize that problem a water-cooled element, so-called "cold aperture", coated with $\mathrm{Al}_{2} \mathrm{O}_{3} / \mathrm{TiO}_{2}$ (with absorption coefficient of $70 \%$ for ECRH stray radiation) is installed inside the endoscope (see Fig. 4).

Choosing a pinhole instead of a window means that a constant influx of plasma impurities will enter inside the endoscope, which will result in a slow degradation of the optical system transmission due to deposition of a: $\mathrm{C}-\mathrm{H}$ layers (especially on the surface of the first mirror - M1). Also due to constant thermal loads the diagnostic water-cooling circuit with water at the pressure of 25 bar is required in order to remove the power from the endoscope front head and the cold aperture in order to keep them at the temperature below $150^{\circ} \mathrm{C}$. Nevertheless, the choice of a pinhole over a front window seems to be optimal, as loss of reflectivity of a mirror is usually lower than loss in transmission of a window given the same coating. Additionally several mitigation measures are applied in order to minimize this issue. An important element is a shutter, which closes the pinhole directly after the discharges to reduce carbon deposition on the mirrors [11] and is closed during plasma vessel conditioning, i.e. glow discharge cleaning and boronisation. Inside the shutter a ceramic heater (made of $\mathrm{Si}_{3} \mathrm{~N}_{4}$ ) is installed for regular transmission monitoring. It will be heated up to $500^{\circ} \mathrm{C}$ on a weekly basis with its temperature measured by a thermocouple as well as by the infrared camera itself at the same time. Changes in the surface temperature detected by the IR camera will allow us to estimate transmission changes of the whole optical system. The same heater can also be heated up to $900^{\circ} \mathrm{C}$ (at which the maximum emission shifts towards 
the visible spectral range) for transmission loss measurements in the visible channels. During a discharge, the ceramic heater will be hidden in a stainless steel pocket in order to avoid exposure to ECRH stray radiation. As most of the incoming impurities will be deposited on the first mirror (M1), it will be equipped with a heater mounted on the back side. As shown in [4], heating it up to $400^{\circ} \mathrm{C}$ will allow removal of most of the deposited a: $\mathrm{C}-\mathrm{H}$ layers. Additionally, we want to test the effectiveness of a flow of hydrogen gas through the observation pinhole on the amount of layers formed on the first mirror which might become particularly important during long pulse plasma operation.

\section{Real-time protection}

During the operation of Wendelstein 7-X the real-time protection of the plasma facing components will be mandatory during plasma operation to avoid degradation of critical plasma facing components. The endoscopes will be used to detect overheated areas on the divertor surface (with temperature above $1000^{\circ} \mathrm{C}$ ), and failures in thermal connection of the graphite elements of the divertor to the cooling structure and symmetry and structure of the power loads in 3D environment of Wendelstein 7-X. As the discharge will be up to 30 minutes long we expect excessive amount of data (up to $2.4 \mathrm{~TB} /$ day) submitted to the image processing routines. Therefore all the data storage, real-time analysis and a major fraction of the post-processing needs to be performed fully automatically. The data processing will be performed with the software packages forming the PiNUP code, which relies on intelligent vision system concepts. The strategy of analysing the infrared images of W7-X divertor is composed of two main tasks: hot spot detection and thermal event recognition [12]. Hot spots on the carbon plasma facing components may appear for a number of reasons:

- Overheating due to excessive power loads. As stated before, target elements are designed to withstand heat fluxes up to a certain level. For instance, baffle structures can cope with steady state heat flux density of up to $0.5 \mathrm{MW} / \mathrm{m}^{2}$. It may happen that due to a change of plasma configuration or bootstrap currents additional power loads reach baffle elements.

- Delaminated carbon tiles will lose their thermal connection to cooling structures of the divertor and therefore will not be able to efficiently remove the power stored in their bulk material. This will result in an elevated CFC temperature.

- Due to carbon erosion and re-deposition thin surface layers are formed on the plasma facing components during plasma operation [13]. Typically they have very a poor thermal connection to the bulk material and therefore heat up very fast and reach much higher temperatures than a virgin surface of the PFCs [14].

- Localised fast particle losses from the neutral beam heating system (NBI) can also produce the hot spots, the duration of the beam injection is up to $10 \mathrm{~s}$.

- $\quad$ Dust particles formed inside the vessel tend to be redeposited during the discharge. As they are poorly thermally connected, they can become very bright,

An intelligent real time protection system, which is based on the imaging of the PFCs with the infrared cameras must be able to classify the events based on their origin. At the moment the algorithms are being developed to aid such classification. One of the methods is to apply transient power fluxes and to observe the time evolution of the surface temperature. Due to vastly different thermal conductivity and thermal capacity, a delaminated tile will show a measurably different response than a healthy tile, or one with surface layers. This has been modeled with the finite element method code ANSYS; results from four studied cases are presented below in Fig. $\mathbf{5}$ where time traces are shown for a load scenario where $10 \mathrm{MW} / \mathrm{m}^{2}$ has been applied for 10 seconds. The reference case is shown in green, a virgin "healthy" tile, where after about $5 \mathrm{~s}$, a thermal equilibrium at $\mathrm{T} \approx 700^{\circ} \mathrm{C}$ is reached. This case has the smallest amplitude of temperature change of the four cases studied. For the second case, a corner delamination with a total surface area of $\Delta \mathrm{s}$ $=58 \mathrm{~mm}^{2}$ is introduced. This does not lead to significant differences in the behaviour of the tile temperatures. For the third case, increasing the delamination area to $\Delta s=116 \mathrm{~mm}^{2}$ leads to a significantly longer time before thermal equilibrium is reached and much higher surface temperatures in equilibrium. Also the cooling after switching off the heat loads takes longer. The fourth case is a tile with surface layers with thickness on the order of a few $\mu \mathrm{m}$ ). This shows a very fast thermal response to the applied power loads due to low thermal capacity of the thin layer and its lack of thermal attachment to the bulk material. This different thermal reaction of the virgin, delaminated and with co-deposits tiles will be used at W7-X to classify the observed areas with elevated temperatures. 


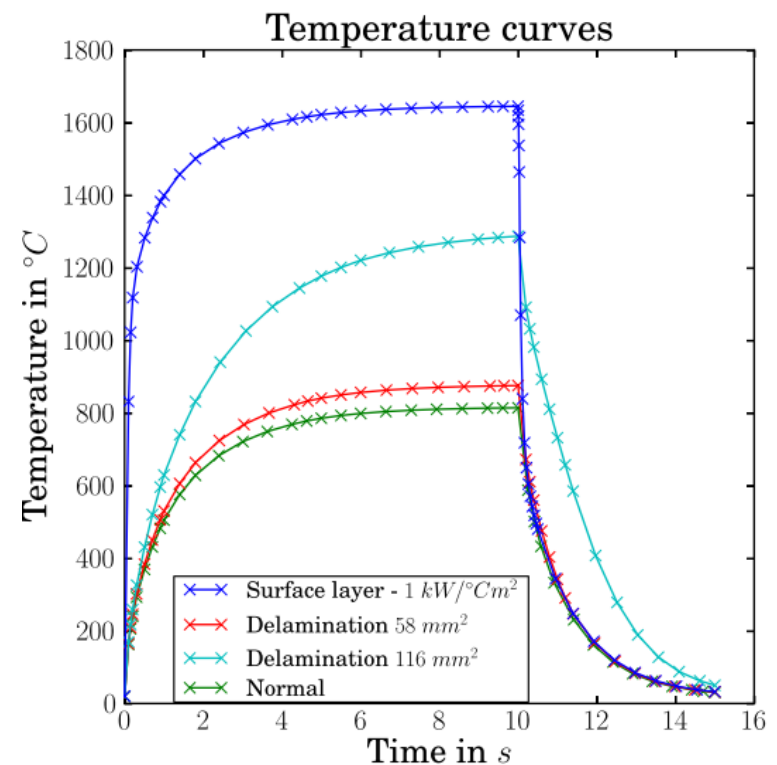

Fig. 5. Finite element calculations of temperature evolution on the W7-X divertor tiles under the heat flux comparable with real experimental conditions. A constant power flux on the surface of (green- virgin tile, red, light blue - delaminated tile and blue $-a$ tile with surface layer on top) is applied from $t=0 \mathrm{~s}$ to $t=10 \mathrm{~s}$.

The real time analysis with PiNUP platform will be performed with the following steps:

1. A data acquisition in real time by 10 infrared cameras monitoring all 10 divertors.

2. A machine control system detects the areas with temperatures above the threshold levels defined a priori by the operator..

3. An event recognition system (software) recognizes different events and classifies them as thermal or plasma events. The events are analyzed thanks to prior knowledge (e.g. detected before delaminated tiles and co-deposits) as well as physic parameters (e.g. discharge scenario parameters).

4. An offline data analysis will be initiated relying on event recognition in order to systematically build a plasma/thermal event data base. The collected semantic information on recognized events can help in a better understanding of plasma wall interactions (e.g. by studying their conditions of occurrence) by means of data mining techniques. The event data bases can also be used to train event recognition algorithms based on machine learning techniques

5. Once a week a discharge is planned to be performed with modulated power loads (e.g. by strike-line movement or injected power variation) in order to be able to detect areas with surface layers. This information will be used to aid the system during event recognition.

\section{Summary}

The design of the steady-state diagnostic for fusion relevant experiments requires careful analysis of the operational conditions. For the IR/VIS endoscope at Wendelstein 7-X the influence of high continuous power loads on the front of the endoscope, the influx of impurities through the pinhole onto the first mirror of the endoscope and the nonabsorbed ECRH stray radiation need to be taken into account. This results in the rather advanced optical and mechanical design of the endoscopes. Real-time processing of the infrared data is a serious challenge for the project. It requires a sophisticated software, which will be able to recognize and classify the events in order to avoid false alarms and at the same time assure safe operation of the experiment under steady-state power loads. 


\section{References}

[1] M. Hirsch, J. Baldzuhn, C. Beidler, R. Brakel, R. Burhenn, a Dinklage, H. Ehmler, M. Endler, V. Erckmann, Y. Feng, J. Geiger, L. Giannone, G. Grieger, P. Grigull, H.-J. Hartfuß, D. Hartmann, R. Jaenicke, R. König, H. P. Laqua, H. Maaßberg, K. McCormick, F. Sardei, E. Speth, U. Stroth, F. Wagner, a Weller, a Werner, H. Wobig, and S. Zoletnik, "Major results from the stellarator Wendelstein 7-AS," Plasma Phys. Control. Fusion, vol. 50, no. 5, p. 053001, May 2008.

[2] V. Erckmann, G. Dammertz, D. Dorst, L. Empacher, W. Forster, G. Gantenbein, T. Geist, W. Kasparek, H. P. Laqua, G. A. Muller, M. Thumm, M. Weissgerber, and H. Wobig, "ECRH and ECCD with high power gyrotrons at the stellarators W7-AS and W7-X," IEEE Trans. Plasma Sci., vol. 27, no. 2, pp. 538-546, Apr. 1999.

[3] R. Konig, P. Grigull, K. McCormick, Y. Feng, J. Kisslinger, A. Komori, S. Masuzaki, K. Matsuoka, T. Obiki, N. Ohyabu, H. Renner, F. Sardei, F. Wagner, and A. Werner, "The divertor program in stellarators," Plasma Phys. Control. Fusion, vol. 44, no. 11, pp. 2365-2422, 2002.

[4] H. Greuner, B. Böswirth, J. Boscary, T. Friedrich, C. Lavergne, C. Linsmeier, J. Schlosser, and A. Wiltner, "Review of the high heat flux testing as an integrated part of W7-X divertor development," Fusion Eng. Des., vol. 84, no. 2-6, pp. 848-852, Jun. 2009.

[5] H. Greuner, B. Boeswirth, J. Boscary, a Leuprecht, and a Plankensteiner, "Power load limits of the WENDELSTEIN 7-X target elements-comparison of experimental results and design values for power loads up to the critical heat flux," Phys. Scr., vol. T128, pp. 218-221, Mar. 2007.

[6] R. König, D. Hildebrandt, T. Hübner, F. Klinkhamer, K. Moddemeijer, and W. Vliegenthart, "Optical design study for divertor observation at the stellarator W7-X," Rev. Sci. Instrum., vol. 77, no. 10, p. 10F121, Oct. 2006.

[7] J. K. Anderson, P. L. Andrew, B. E. Chapman, D. Craig, and D. J. Den Hartog, "Direct removal of edge-localized pollutant emission in a near-infrared bremsstrahlung measurement," Rev. Sci. Instrum., vol. 74, no. 3, p. 2107, Mar. 2003.

[8] Y. Feng, F. Sardei, P. Grigull, K. McCormick, J. Kisslinger, and D. Reiter, "Physics of island divertors as highlighted by the example of W7-AS," Nucl. Fusion, vol. 46, no. 8, pp. 807-819, Aug. 2006.

[9] Y. Feng, M. Kobayashi, F. Sardei, S. Masuzaki, J. Kisslinger, T. Morisaki, P. Grigull, H. Yamada, K. McCormick, N. Ohyabu, R. Konig, I. Yamada, L. Giannone, K. Narihara, U. Wenzel, S. Morita, H. Thomsen, J. Miyazawa, D. Hildebrandt, T. Watanabe, F. Wagner, N. Ashikawa, K. Ida, A. Komori, O. Motojima, Y. Nakamura, B. J. Peterson, K. Sato, M. Shoji, N. Tamura, M. Tokitani, and the L. experimental group, "Comparative divertortransport study for helical devices," Nucl. Fusion, vol. 49, no. 9, p. $095002,2009$.

[10] R. König, O. Ogorodnikova, D. Hildebrandt, K. Grosser, C. von Sehren, J. Baldzuhn, R. Burhenn, P. Mertens, A. Pospieszczyk, B. Schweer, H. Schmidt, and T. Klinger, "Development of cooled UV, visible and IR windows for quasicontinuous operation of the W7-X stellarator," Rev. Sci. Instrum., vol. 75, no. 10, pp. 4258-4260, Oct. 2004.

[11] A. von Keudell, C. Hopf, T. Schwarz-Selinger, and W. Jacob, "Surface loss probabilities of hydrocarbon radicals on amorphous hydrogenated carbon film surfaces: Consequences for the formation of re-deposited layers in fusion experiments," Nucl. Fusion, vol. 39, no. 10, pp. 1451-1462, Oct. 1999.

[12] J. Travere, M.-H. Aumeunier, M. Joanny, M. Jouve, V. Martin, V. Moncada, S. Salasca, L. Marot, D. Chabaud, J.J. Ferme, F. Bremond, and M. Thonnat, "The ITER VIS/IR wide angle viewing system: Challenges and on-going R\&D," Advancements in Nuclear Instrumentation Measurement Methods and their Applications (ANIMMA), 2011 2nd International Conference on. pp. 1-9, 2011. 
http://dx.doi.org/10.21611/qirt.2014.100

[13] J. Likonen, J. P. Coad, E. Vainonen-Ahlgren, T. Renvall, D. E. Hole, M. Rubel, and A. Widdowson, "Structural studies of deposited layers on JET MkII-SRP inner divertor tiles," J. Nucl. Mater., vol. 363-365, no. null, pp. 190195, Jun. 2007.

[14] D. Hildebrandt, "Thermographic observation of the divertor target plates in the stellarators W7-AS and W7-X," J. Nucl. Mater., vol. 313-316, pp. 738-742, Mar. 2003. 